\title{
Isolation and Characterization of the Beadex Locus of Drosophila melanogaster: a Putative cis-acting Negative Regulatory Element for the heldup- $a$ Gene
}

\author{
WILLIAM W. MATTOX ${ }^{1}$ AND NORMAN DAVIDSON ${ }^{2 *}$ \\ Division of Biology ${ }^{1}$ and Department of Chemistry, ${ }^{2}$ California Institute of Technology, Pasadena, California 91125
}

Received 6 February 1984/Accepted 19 April 1984

\begin{abstract}
We isolated recombinant lambda phage clones spanning 49 kilobases of DNA which contain the Beadex and heldup-a loci of Drosophila melanogaster. These cloned DNAs were used to analyze the structure of eight dominant mutant alleles of the Beadex locus which show increased gene activity. A region, only 700 base pairs in length, is altered in each of these mutants. Six of the mutations have DNA insertions within this segment. Most of these insertions resemble retrovirus-like transposable elements. In one case (Beadex $\left.{ }^{2}\right)$ the inserted sequences are homologous to the gypsy transposon family. The other two Beadex alleles were induced by hybrid dysgenesis and suffered deletions which included at least part of the 700-base-pair segment. These deletions appear to have resulted from imprecise excision or deletion of a nearby $P$ element found in the wild-type parental strain. Analysis of one heldup- $a$ allele (heldup- $a^{D 30 r}$ ) indicates that a similar P element-mediated event is responsible for this lesion. In this mutant, deletion of sequences no more than 1,600 base pairs from the Beadex locus accompanies the loss of heldup-a function. The deleted sequences in heldup- $a^{D 30 r}$ include the entire 700-base-pair segment within which at least part of the Beadex locus resides, yet these flies have no Beadex phenotype. This indicates that a functional heldup-a gene is necessary for expression of the Beadex phenotype. Together, these results suggest that the Beadex functional domain is contained within a short segment of DNA near the heldup-a gene and support the hypothesis that the Beadex locus functions as a cis-acting negative regulatory element for the heldup-a gene.
\end{abstract}

Very few eucaryotic loci have been identified where mutations cause abnormally high levels of gene activity and result in a visible phenotype $(7,18,39)$. The $17 \mathrm{BC}$ segment of the Drosophila melanogaster X-chromosome contains such a locus. Simple duplications including this chromosomal segment cause a characteristic loss of tissue along the wing borders (wing scalloping) $(16,17)$. Triplications which include $17 \mathrm{BC}$ cause more severe wing scalloping, and flies with quadruplications are still more severely affected $(16,17$, 24). Thus, the degree of wing scalloping appears to be related to the increased activity of some gene within this segment.

Although gross deficiencies which include the 17BC segment have no dominant effect on wing phenotype $(D \mathrm{f} /+$ is wild type), several dominant wing-scalloping mutations have been mapped to the Beadex $(B x)$ locus which is located within this segment at map position 1-59.4 (see Table 1). The $17 \mathrm{BC}$ segment is not visibly altered or duplicated in any of these $B x$ alleles, suggesting that they are simple mutations at the $B x$ locus and are not associated with increased gene dosage (unpublished data). The phenotypic similarity of these $B x$ mutants to flies with multiple doses of the 17BC segment suggests that mutations at the Beadex locus lead to an increase in the wild-type activity of a gene within the $17 \mathrm{BC}$ segment. This idea is supported by the interactions of these mutations with deficiencies and duplications that include $17 \mathrm{BC}$. Flies bearing a $B x$ mutation on one homologue and a duplication of the wild-type 17BC segment on the other have an enhanced Beadex phenotype, whereas deficiencies suppress $B x$ mutations. For instance, the weakly dominant mutant allele $B x^{l}$ is totally suppressed by any deficiency which includes $17 \mathrm{BC}$, but wing scalloping is enhanced by duplications including this segment $\left(B x^{1} / D f<B x^{l} /+<B x^{l} /\right.$ $D p)(16,17,24)$. Strong $B x$ alleles are only partially sup-

\footnotetext{
* Corresponding author.
}

pressed by deficiencies (24). These observations strongly suggest that the $B x$ locus has a regulatory function and that mutations at this locus lead to an increase in the normal activity of some nearby structural gene rather than a loss or qualitative alteration of the activity of that gene product.

Mutations which result in loss of $B x$ activity have been isolated as phenotypic revertants and suppressors of $B x$ mutant alleles (24). These mutations fall into two classes: gross deletions including the $17 \mathrm{BC}$ region and point mutations in the closely linked heldup- $a$ ( $h d p-a)$ gene (see Table $1)$, which is also within 17BC. These hdp-a mutations completely suppress even strong $B x$ alleles in cis and mimic the partial suppression of $B x$ exhibited by deficiencies in trans. hdp-a mutations themselves are associated with a recessive heldup wing position phenotype (25). Lifschytz and Green (24) showed that the $B x$ and $h d p-a$ loci are separated by only 0.0045 map units and that one $h d p-a$ allele maps to the centromere distal side of $B x^{3}$. They proposed a model, based on the interactions of these two loci, in which the wild-type $B x$ locus functions as a cis-acting negative regulatory element for the adjacent $h d p-a$ structural gene (24). In this model mutations at the $B x$ locus would result in an increase in $h d p-a^{+}$activity. The wing-scalloping phenotype observed in $B x$ mutants would be a result of this increased $h d p-a^{+}$activity. Mutations in the $h d p-a$ structural unit, which eliminate $h d p-a^{+}$activity, result in a heldup wing position phenotype with no wing scalloping. In the cis double mutant ( $h d p-a B x$ ), disruption of the $h d p-a$ gene would preclude any hyperactivity due to the $B x$ mutation. Thus $h d p$ - $a$ mutations suppress $B x$ alleles in cis.

A rigorous test of this model requires both quantitative and qualitative characterization of the $h d p-a$ gene product in both $B x$ and $h d p-a$ mutant flies. Here we report the isolation of DNA sequences corresponding to at least part of both the $B x$ and $h d p-a$ loci. These cloned DNA sequences should 
allow us to identify any RNA molecules encoded by these genetic elements.

In the course of identifying these DNA sequences we studied the molecular structure of a number of $B x$ mutations and one $h d p-a$ allele. We report here that all the $B x$ mutations we examined have alterations in a single 700-base-pair region. Six $B x$ alleles contain DNA insertions in this region, whereas two alleles, which were induced by hybrid dysgenesis, are the result of imprecise $\mathrm{P}$ element excisions or deletions which remove sequences from this segment. A single $h d p-a$ mutation, which is associated with a similar hybrid dysgenic event, suggests that part of the hdp-a locus resides no more than 1,600 base pairs from the $B x$ locus.

\section{MATERIALS AND METHODS}

Fly stocks. Mutant fly stocks were obtained from The Drosophila Stock Center at the California Institute of Technology, The Mid-America Drosophila Stock Center at Bowling Green University, W. Baker at the University of Utah, and W. Engels at the University of Wisconsin. The $B x$ and $h d p$ - $a$ mutant strains used in this work are described in Table 1.

In situ hybridizations to polytene chromosomes. Drosophila melanogaster salivary gland squashes were prepared as described by Gall and Pardue (15) except that the acid treatment was omitted. Each squash was hybridized with $10^{6}$ cpm of $\left[{ }^{3} \mathrm{H}\right] \mathrm{cRNA}$ in $50 \%$ formamide (deionized)-0.75 M sodium chloride- $0.075 \mathrm{M}$ sodium citrate- $5 \mathrm{mg}$ of calf liver tRNA per ml (Sigma Chemical Co.). Slides were washed, autoradiographed, and stained with Giemsa solution (AccraLabs, Inc.) as described by Gall and Pardue (15).

Construction of cosmid libraries. Ten micrograms of highmolecular-weight Drosophila genomic DNA was digested in separate reactions with $0.005,0.02,0.04,0.06,0.10$, and 0.16 $\mathrm{U}$ of $\mathrm{MboI}$ (New England Biolabs) per $\mu \mathrm{g}$ for $12 \mathrm{~min}$ at $37^{\circ} \mathrm{C}$ $(60 \mu \mathrm{g}$ total). The reaction with the lowest amount of enzyme yielded $\mathrm{MboI}$ fragments with an average size greater than $\mathbf{5 0}$ kilobases $(\mathrm{kb})$, whereas the reaction containing the largest amount yielded fragments averaging ca. $10 \mathrm{~kb}$ in length. These digests were pooled and digested with calf intestine alkaline phosphatase and then sedimented through a 10 to $40 \%$ linear sucrose gradient (1 M sodium chloride, $0.02 \mathrm{M}$ Tris-hydrochloride [pH 8.0], 0.01 M EDTA) in a Beckman $\mathrm{SW} 27.1$ rotor at $22,000 \mathrm{rpm}$ for $24 \mathrm{~h}$ at $20^{\circ} \mathrm{C}$. Fractions

TABLE 1. Mutant fly strains used to isolate DNA

\begin{tabular}{|c|c|c|}
\hline Strain & $\begin{array}{l}\text { Wing-scalloping } \\
\text { phenotype }\end{array}$ & Origin (reference) \\
\hline$\overline{B x^{l}}$ & Weak & Spontaneous (25) \\
\hline$B x^{2}$ & Moderate & Spontaneous (25) \\
\hline$B x^{3}$ & Moderate & Spontaneous (14) \\
\hline$B x^{J}$ & Strong & Heat induced (22) \\
\hline$B x^{46}$ & Moderate & Unknown \\
\hline Inscy $w B x^{M}$ & Weak & $\begin{array}{l}\text { Spontaneous in Inscy } w \text { found } \\
\text { by Muller }\end{array}$ \\
\hline$B x^{9}$ & Strong & $\begin{array}{l}\text { Hybrid dysgenesis induced on } \\
\text { the } \pi_{2} \text { X-chromosome by } \\
\text { W. Engels }\end{array}$ \\
\hline$B x^{15}$ & Strong & $\begin{array}{l}\text { Hybrid dysgenesis induced on the } \\
\pi_{2} \mathrm{X} \text {-chromosome by W. Engels }\end{array}$ \\
\hline$h d p-a^{D 30 r^{a}}$ & Wild & $\begin{array}{l}\text { Hybrid dysgenesis induced on the } \\
\pi_{2} \text { X-chromosome by W. Engels }\end{array}$ \\
\hline
\end{tabular}

${ }^{a}$ Several different genes have been called heldup $(10,13,24)$. Here we designate the suppressor of Beadex as $h d p-a$ and the closely linked mutations described by Engels as $h d p-b$. $h d p-a$ and $h d p-b$ fall into separate complementation groups (unpublished data). containing $36-$ to $42-\mathrm{kb} \mathrm{MboI}$ fragments were pooled and dialyzed against $200 \mathrm{mM}$ sodium chloride-10 $\mathrm{mM}$ Trishydrochloride ( $\mathrm{pH}$ 7.6)-1 mM EDTA. This DNA was concentrated by ethanol precipitation and ligated with an equal mass $(6 \mu \mathrm{g})$ of pJB8 DNA, which was prepared as described by Ish-Horowicz and Burke (21). Cosmid DNA was packaged in vitro by using the protocol of Mullins et al. (30). We obtained a total of about $2 \times 10^{5}$ ampicillin-resistant colonies (equivalent to 46 Drosophila haploid genomes) when these packaged cosmids were transfected into Escherichia coli HB101. The inserts in 12 randomly selected clones ranged in size from 31 to $41 \mathrm{~kb}$ and averaged $37 \mathrm{~kb}$.

We found that omission of the size selection step led to much poorer efficiencies (less than $10^{2}$ colonies per $\mu \mathrm{g}$ of target DNA), presumably due to the molar excess of small MboI fragments which ligated with PJB8 to form molecules too small to package.

Screening of phage and cosmid genomic libraries. The $B x^{2}$ cosmid library was screened by the colony hybridization method of Hanahan and Meselson (20) with the modifications added by Grosveld et al. (19). The Canton-S Charon 4 phage library (26) was screened by the method of Benton and Davis (3).

Isolation of DNA. Cosmid and plasmid DNA were isolated as described by Steinmetz et al. (41) except that bacteria were grown in medium containing $100 \mathrm{mg}$ of ampicillin per liter rather than tetracycline. Recombinant phage for DNA isolation were grown by the PDS method of Blattner et al. (6). Phage were precipitated with polyethylene glycol and sodium chloride as described by Yamamoto et al. (44). They were then purified by $\mathrm{CsCl}$ equilibrium centrifugation, and DNA was isolated as described by Maniatis and co-workers (26). Drosophila genomic DNA was isolated from adult flies as described by Davis and Davidson (8).

DNA blot hybridizations. DNA was digested with a fivefold excess of restriction endonucleases purchased from New England Biolabs or Boehringer Mannheim. After agarose gel electrophoresis, the digested DNA was transferred to nitrocellulose (40). Blots were incubated with denatured probe, washed, and autoradiographed as described by Rozek and Davidson (34). Radioactive probes were removed from blots by washing twice for $30 \mathrm{~s}$ with $0.015 \mathrm{M} \mathrm{NaCl}-0.0015 \mathrm{M}$ sodium citrate $(\mathrm{pH} 7.5)$ at $100^{\circ} \mathrm{C}$.

In vitro labeling of nucleic acids. $\left[{ }^{3} \mathrm{H}\right] \mathrm{cRNA}$ was prepared as described by Wensink et al. (43). DNA was nick translated as outlined by Rigby and co-workers (33). For the uniform labeling of BamHI fragments from p24R8.0B, this plasmid was digested to completion with BamHI and labeled with $\left[{ }^{32} \mathrm{P}\right] \mathrm{dGTP}$ by using the large fragment of DNA polymerase I (Boehringer Mannheim) (27).

Electron microscopy. SalI-cut $\mathrm{cBx}^{2} 17 \mathrm{C}-1(0.1 \mu \mathrm{g})$ was denatured in $0.1 \mathrm{~N} \mathrm{NaOH}$ for $30 \mathrm{~s}$ at $0^{\circ} \mathrm{C}$ and then neutralized with Tris-hydrochloride. This was diluted to $0.5 \mu \mathrm{g} / \mathrm{ml}$ in a solution containing $50 \%$ formamide, $0.1 \mathrm{mg}$ of cytochrome $c_{1}$ per $\mathrm{ml}, 100 \mathrm{mM}$ Tris-hydrochloride $(\mathrm{pH} 8.5)$, and $10 \mathrm{mM}$ EDTA and immediately spread for electron microscopy as described by Davis et al. (9).

\section{RESULTS}

Strategy for molecular cloning of the Beadex locus. To isolate recombinant clones containing DNA from the $B x$ locus, we used a modification of the transposon-tagging approach first suggested by Bingham et al. (5). The mutant allele $B x^{2}$ is suppressed in flies homozygous for a mutation at the unlinked suppressor of Hairy-Wing $[s u(H w)]$ locus $(23$, 25). Since a variety of Drosophila mutations, which are 
suppressed by $s u(H w)$ possess DNA from the gypsy transposon family at the mutated locus (29), we examined the possibility that $B x^{2}$ possesses a gypsy transposon at the $B x$ locus. $B x^{2}$ polytene chromosomes were hybridized with $\left[{ }^{3} \mathrm{H}\right] \mathrm{cRNA}$ made from $\lambda \mathrm{bx}^{34 \mathrm{e}}-6 \mathrm{a} 2$ recombinant phage DNA (a gift from W. Bender) in situ. This phage contains about 7 $\mathrm{kb}$ of unique sequences from the bithorax region, as well as one copy of the 7.3-kb gypsy transposon. The chromosome in Fig. la shows the expected hybridization at the $89 \mathrm{E}$ region of the third chromosome (bithorax), as well as hybridization to the 17C segment of the X-chromosome (Beadex). No other sites of localized hybridization were observed; however, a number of grains were consistently visible over the chromocenter. We presume that these grains represent hybridization to gypsy sequences in heterochromatin. Indeed, whole genome Southern blots with $B x^{2}$ DNA revealed 6 to 10 different sites of gypsy insertion in the $B x^{2}$ genome (data not shown).
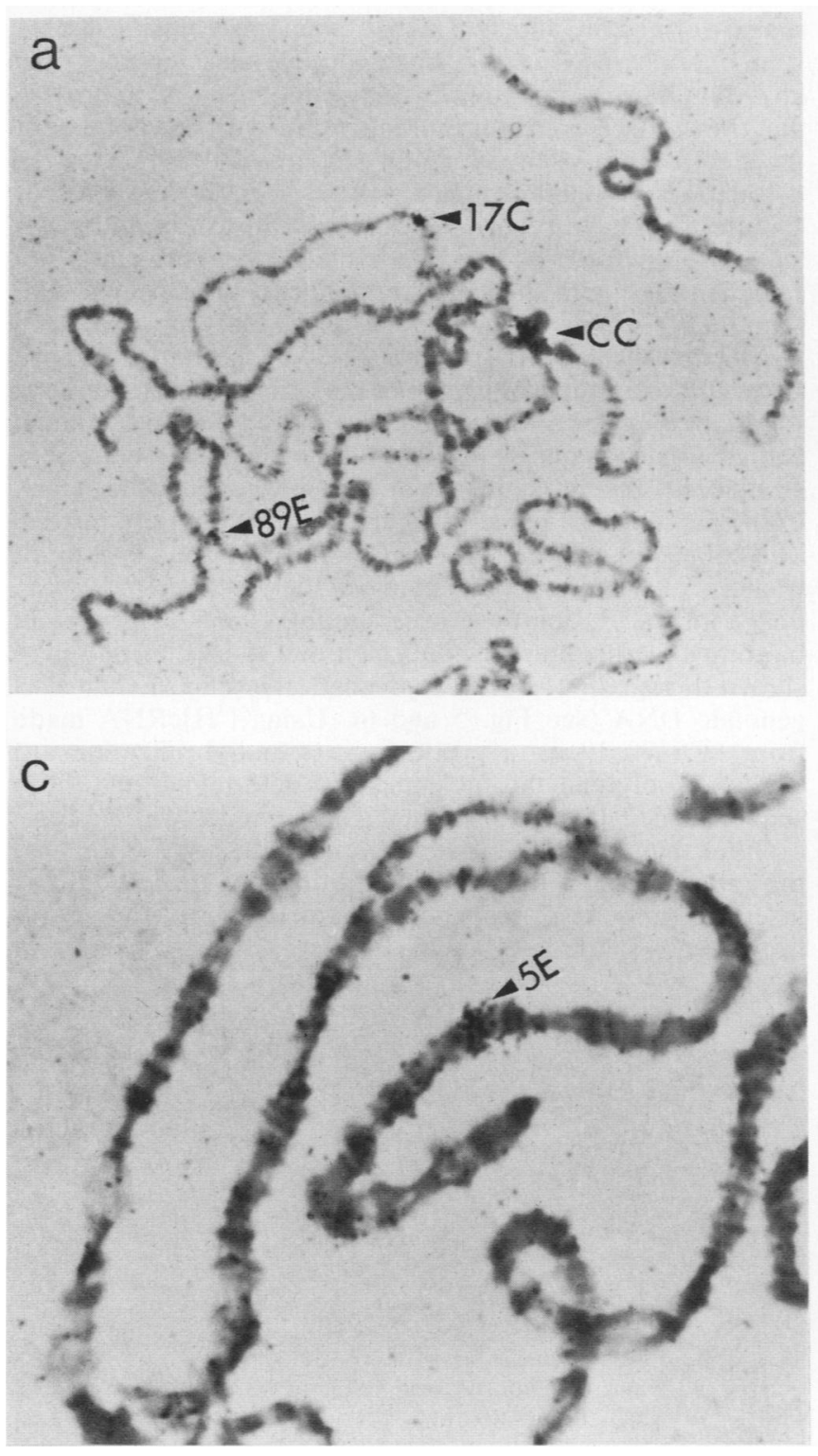

FIG. 1. In situ hybridizations with $\left[{ }^{3} \mathrm{H}\right] \mathrm{RNA}$ made from: (a) $\lambda b \mathrm{bx}^{34 \mathrm{e}} \mathrm{-6a} 2$ and hybridized with $B x^{2}$ polytene chromosomes, (b) $\lambda C S 17 \mathrm{C}-19$ and hybridized to Canton-S chromosomes, (c) $\lambda$ CS17C-2 and hybridized to homozygous In(l)D6j chromosomes, or (d) $\lambda$ CS17C-9 and hybridized to homozygous $\operatorname{In}(I) D 6 j$ chromosomes. Arrows point to sites of consistent hybridization. cc, Chromocenter.
To isolate $B x$ sequences by transposon tagging, clones containing the gypsy transposon from $17 \mathrm{C}$ must be identified. We took advantage of a $P$ element, which is within polytene bands $17 \mathrm{C} 2-3$ in the strain $\pi_{2}$, to identify such clones. Genetic experiments indicate that this $\mathrm{P}$ element lies near the $B x$ locus (see below). Since the 17C2-3 P element from $\pi_{2}$ had already been isolated (31), a probe, $\mathrm{pS} 25.1$ containing only unique sequences from the $17 \mathrm{C} 2-3$ region was available. This plasmid contains a 1.8-kb Bam HI fragment, from the wild-type strain Canton-S, which is homologous to the DNA immediately flanking the 17C2-3 P element of $\pi_{2}$ but contains no P sequences. Any gypsy homologous recombinant clones from a $B x^{2}$ genomic library which hybridize with this fragment must contain the gypsy element residing near $17 \mathrm{C} 2-3$.

$B x^{2}$ has two gypsy elements inserted in opposite orientation at $17 \mathrm{C} 2-3$. A cosmid library containing $B x^{2}$ genomic sequences was constructed by using the vector pJB8 (see
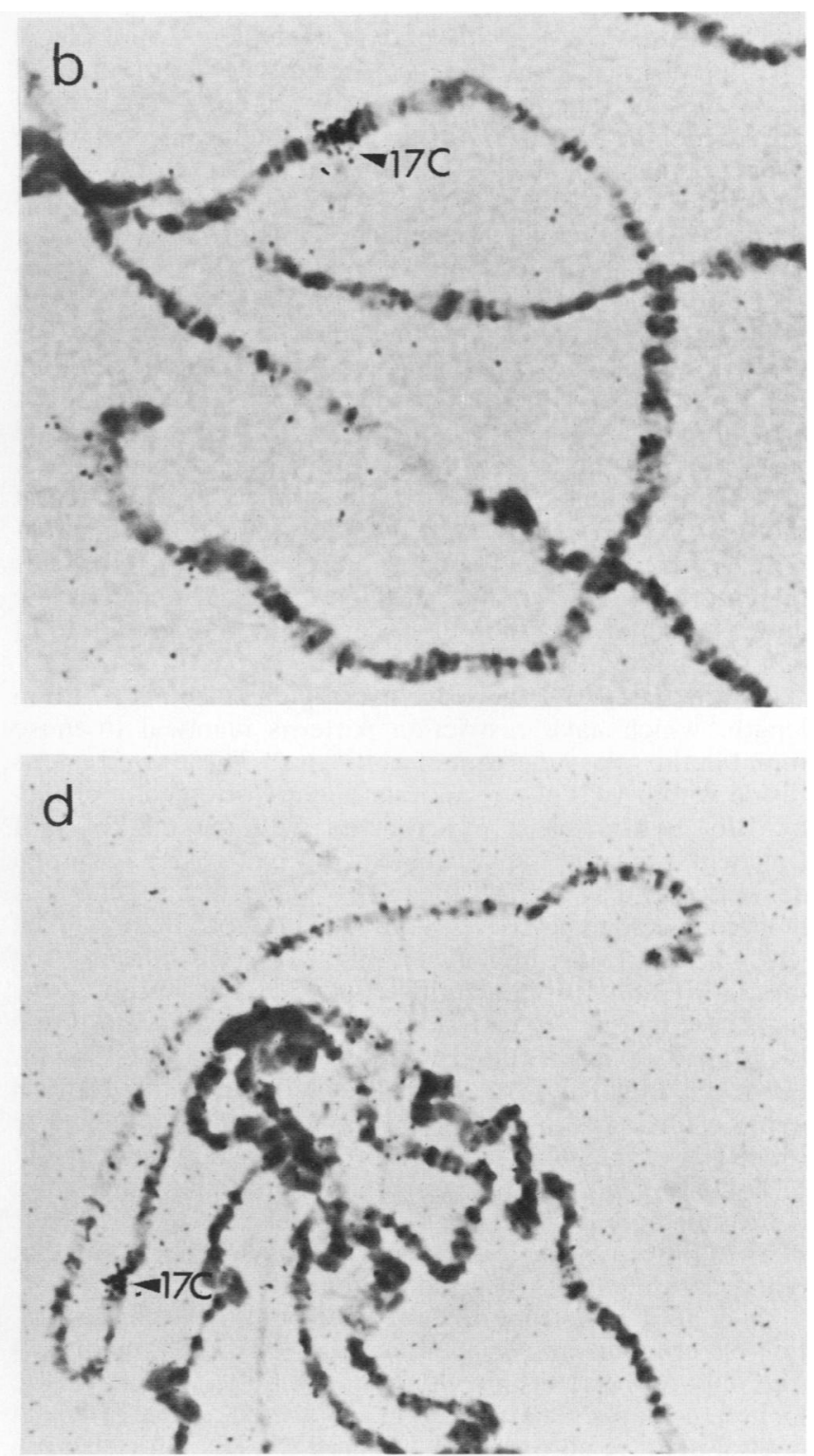


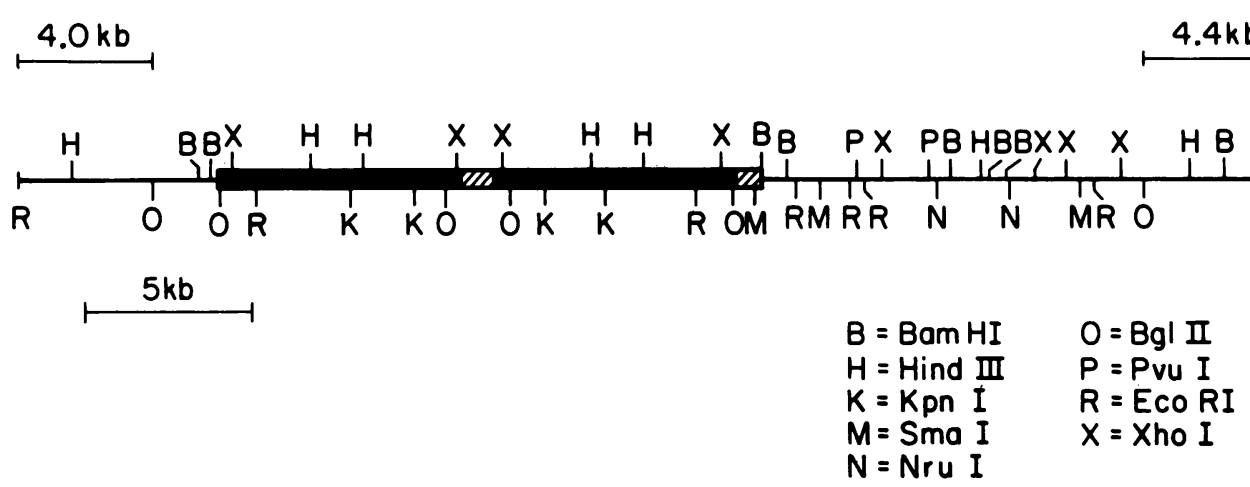

FIG. 2. Restriction map of the $\mathrm{cBx} x^{2} 17 \mathrm{C}-1$ insert. The insert is flanked on both ends by $E c o$ RI sites which are not present in the $B x^{2}$ genome. The heavy lines indicate sequences which are homologous to gypsy element DNA. The hatched regions designate homology to the 1.8-kb BamHI fragment from pS25.1. The bars above the restriction map indicate fragments used as probes to isolate recombinant phage clones from the Canton-S Charon 4 library.

above). Three Drosophila genome equivalents were plated by using the recA- $A^{-}$host HB101. These clones were screened in parallel for homology to the $1.8-\mathrm{kb} B a m$ HI fragment of pS25.1 and the 6.8-kb XhoI fragment which is internal to the gypsy element in $\lambda b x^{34 e}-6 a 2$. Since $X h o I$ cuts only in the terminal direct repeats of the gypsy element, this $6.8-\mathrm{kb}$ fragment contains all sequences within the transposon. Twenty-three positive clones were identified with the gypsy probe and only two with the 1.8-kb BamHI fragment. Both of the latter were also among the gypsy homologous set. One of these clones was lost during subsequent rescreening; the other was isolated and designated $\mathrm{cBx}^{2} 17 \mathrm{C}-1$. Cosmid DNA was prepared from this clone and digested with several restriction enzymes to generate the map shown in Fig. 2. $\mathrm{cBx}^{2} 17 \mathrm{C}-1$ contains $42 \mathrm{~kb}$ of $B x^{2}$ genomic DNA inserted at the BamHI site of PJB8. Genomic blots with cloned Canton$S$ DNA from the same region as a probe confirmed that this map represents the configuration on the $B x^{2} \mathrm{X}$-chromosome and is not an artifact of in vivo manipulation or growth in $E$. coli (see below).

Within $\mathrm{cBx}^{2} 17 \mathrm{C}-1$ there are two regions, each $\mathrm{ca} .7 \mathrm{~kb}$ in length, which have restriction patterns identical to those found in the gypsy element of $\lambda b x^{34 e}-6 a 2$. These two regions reside within $1 \mathrm{~kb}$ of one another and are oriented oppositely. Blot hybridization experiments with the $6.8-\mathrm{kb}$ XhoI fragment from the gypsy element in $\lambda b x^{34 \mathrm{e}}-6 \mathrm{a} 2$ as a probe demonstrate that each of these two gypsy-like segments is homologous to gypsy DNA (data not shown). The regions of gypsy homology are indicated in Fig. 2. Hybridizations using the $1.8-\mathrm{kb}$ BamHI fragment insert of $\mathrm{pS} 25.1$ as a probe show that these unique sequences lie between and adjacent to the two gypsy elements found in $\mathrm{cBx}^{2} 17 \mathrm{C}-1$ (data not shown). However, fragments which span the left end of the leftward gypsy element (as they are shown in Fig. 2) do not hybridize to the $1.8-\mathrm{kb}$ fragment. Our interpretation is that the segment of homology within these fragments is too short to form a detectable hybrid (since the BamHI site is less than 100 base pairs to the left of the left end of the gypsy element) and that both gypsy elements inserted into the 1.8-kb fragment.

To confirm the structure deduced from the blot hybridization experiments above, we linearized $\mathrm{cBx}^{2} 17 \mathrm{C}-1$ with SalI (the only SalI site in this clone is within the vector, pJB8), melted the duplex in alkali, allowed it to self-anneal briefiy at neutral pH (see above), and prepared the DNA for electron microscopy. A stem-loop structure was consistently observed. An example is shown in Fig. 3. This stem-loop structure is of the proportions predicted for the inverted repeat formed by the two gypsy elements, with a duplex stem of about $7.5 \mathrm{~kb}$ and a single-stranded loop of about 0.9 $\mathrm{kb}$. No bubbles were observed in the duplex stem, indicating that the two gypsy elements are identical with one another at the electron microscope level of resolution.

Isolation of clones containing wild-type DNA from 17C2-3. To study the wild-type Beadex locus and to obtain singlecopy probes for whole genome blotting experiments, we screened a random shear Charon 4 library constructed with Canton-S genomic DNA (26) by using the 4.0 and $4.4-\mathrm{kb}$ $B g$ III-EcoRI fragments from $\mathrm{cBx}^{2} 17 \mathrm{C}-1$ (see Fig. 2). These fragments are at opposite ends of the cosmid insert, allowing isolation of clones covering a large region. From five genome equivalents screened with these ${ }^{32} \mathrm{P}$-labeled fragments, seven different recombinant phage clones were isolated. DNA from each of these phages was mapped for restriction sites. The composite map is shown in Fig. 4a. A total of $49 \mathrm{~kb}$ of Canton-S DNA is represented in the seven overlapping phage inserts. Using these overlapping clones as probes in blotting experiments, we confirmed that the restriction map shown in Fig. 4a correctly represents the map of Canton-S genomic DNA (see Fig. 5 and 6). Using $\left[{ }^{3} \mathrm{H}\right]$ cRNA made from $\lambda \mathrm{CS} 17 \mathrm{C}-19$ as a probe in in situ hybridizations to Canton-S polytene chromosomes, we determined that these sequences localize uniquely at $17 \mathrm{C}$, as expected (Fig. 1b).

Other than several simple restriction site polymorphisms, the map in Fig. 4 differs from the map of the $\mathrm{cBx}^{2} 17 \mathrm{C}-1$ insert in only two respects: the absence of the gypsy transposons found in $\mathrm{CBx}^{2} 17 \mathrm{C}-1$ (these would be inserted at
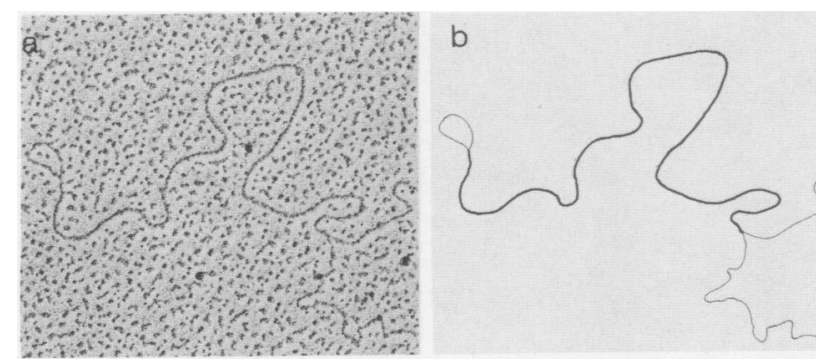

FIG. 3. Electron micrograph of linearized self-annealed cBx ${ }^{2}$ 17C-1 DNA. (a) Photograph, (b) schematic representation of photograph. Measurements on five such stem-loop structures were made by using pBR322 as a double-stranded size standard and $\phi X 174$ DNA as a single-stranded standard. The average size was ca. $7.5 \mathrm{~kb}$ for the stem and about $0.9 \mathrm{~kb}$ for the single-stranded loop. 
A

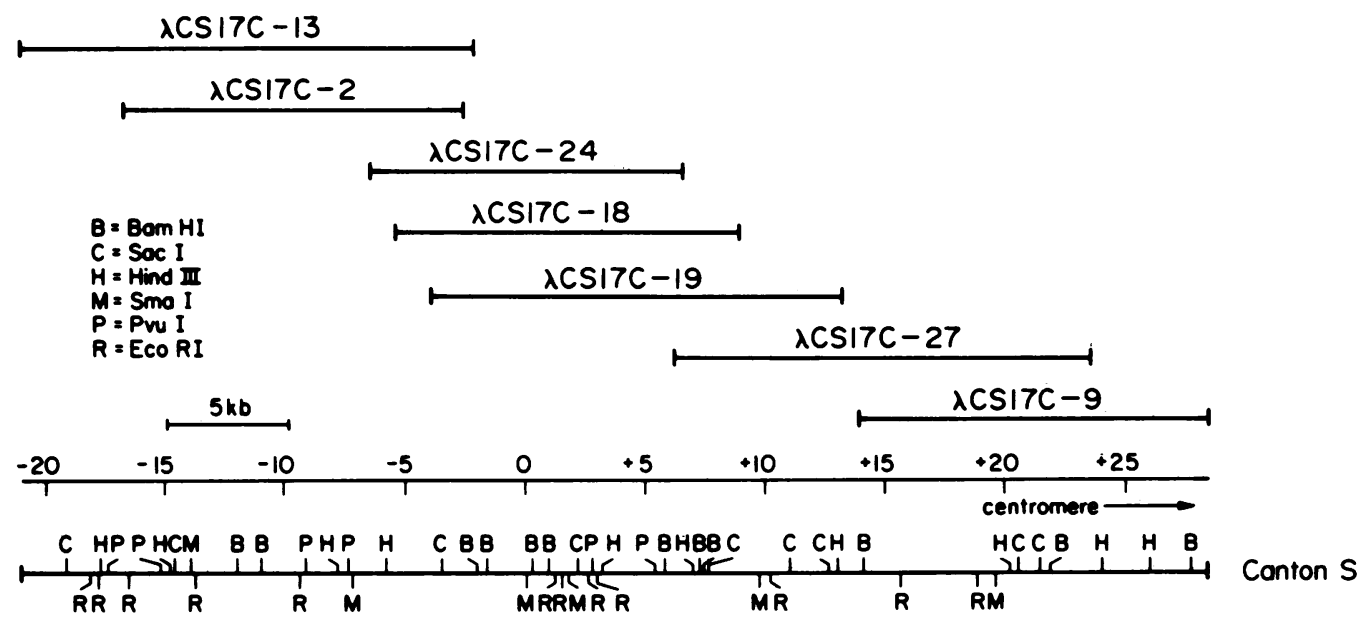

B

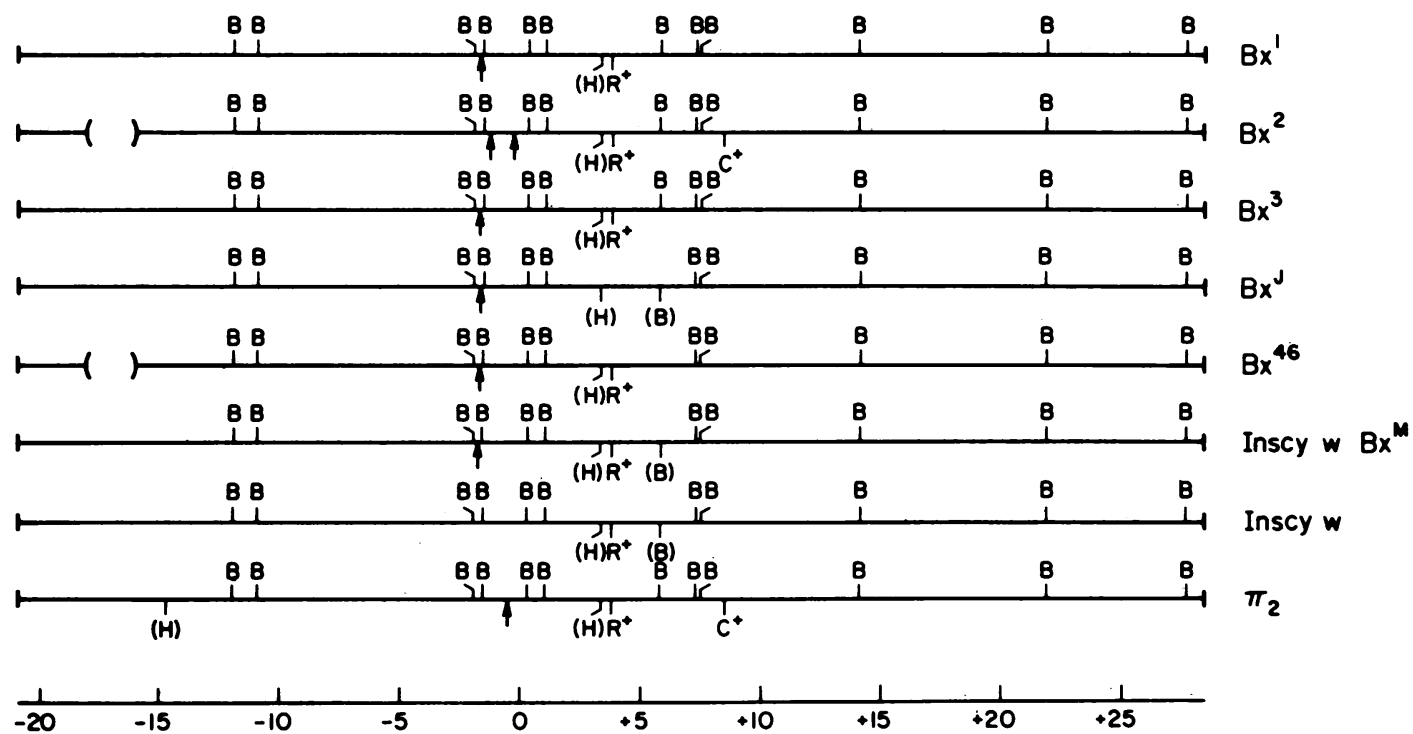

FIG. 4. Composite restriction maps of both wild-type and mutant strains from the Beadex-heldup-a region. (A) Restriction map of Canton$S$ was deduced from the maps of recombinant phage clone inserts and confirmed by blot hybridization by using Canton-S genomic DNA. The segment covered by each phage insert is shown above the restriction map. The SmaI site in the 1.8-kb Bam HI fragment was arbitrarily assigned coordinate position 0.0 . Sequences on the centromere proximal side (right) of this site are given positive coordinates corresponding to their distance in kilobases from the 0.0 position. Sequences to the left are given negative coordinates in the same manner. (B) Composite maps of Beadex mutants and their parental strains deduced by blot hybridizations. The BamHI sites are shown in each case for reference. Differences relative to Canton-S are indicated below the line in each case. Sites not present in the mutant strain are indicated with parentheses. Sites which are found in the mutant but not Canton-S are identified with a + . Maps of the insertions are not included, but their positions are indicated by the arrows. Maps for the inserted elements can be found in Fig. 2, 8, and 9. Note that the Inscy $w$ and $\pi_{2}$ strains are both $\mathrm{Bx}^{+}$.

coordinate positions -0.5 and -1.5 in Fig. 4) and a deletion of 50 to 100 base pairs somewhere between coordinates +1.4 and +2.0 . This small deletion seems to be a peculiarity of the Canton-S strain, since whole genome blotting analysis of eight $B x$ mutant strains and two other $B x^{+}$strains failed to reveal another example (see the 2.0-kb $S m a I$ fragment in Fig. 5b).

Determination of the chromosomal orientation of cloned DNA. Genetic mapping experiments have placed the $B x$ locus a short distance to the proximal side of the $h d p$ - $a$ locus (24). Since mutations at these two loci are known to interact in cis, we were interested in determining the molecular structure of both $h d p-a$ and $B x$ functional domains. Relating the genetic positions of these loci to our restriction map requires a knowledge of the chromosomal orientation of the cloned DNA. We determined this by using a large inversion which has one breakpoint in the cloned region. This inversion, called $\operatorname{In}(1) D 6 j$, was induced by hybrid dysgenesis in the strain $\pi_{2}$ and includes the region between 5E3-7 and $17 C 2-3(3,12)$. Blotting analysis indicates that the 17C2-3 breakpoint is between coordinates -1.6 and +0.2 (W. Engels and C. Preston, personal communication). This places the endpoint within or very close to the resident $\mathrm{P}$ element found at -0.8 in $\pi_{2}$ flies (see Fig. 8) (31). Separately, we 

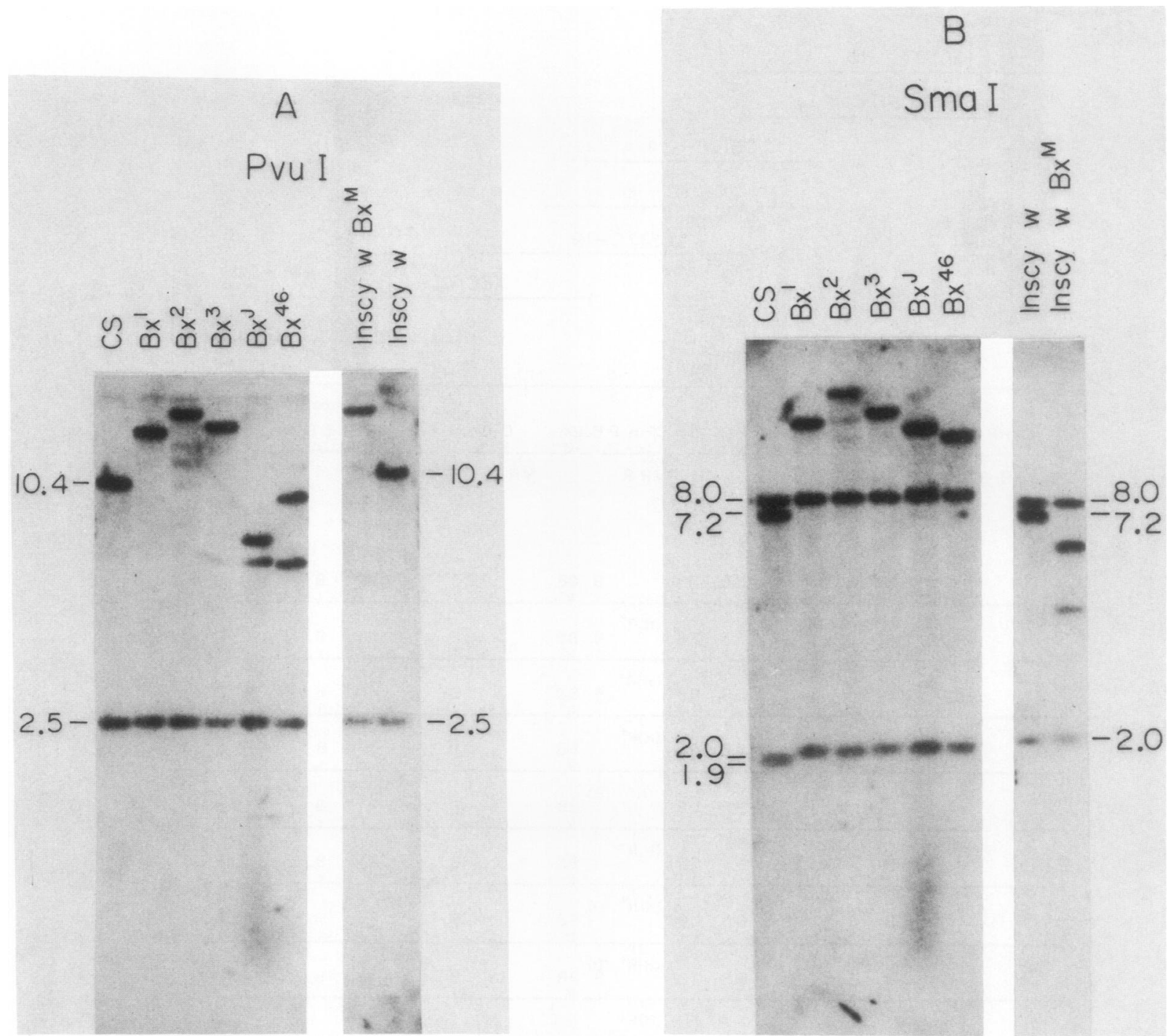

FIG. 5. Restriction-digested Beadex and wild-type DNAs. Each blot was probed with ${ }^{32}$ P-labeled $\lambda C S 17 C-24$ DNA. (A) PvuI-digested genomic DNAs. (B) SmaI-digested genomic DNAs.

hybridized $\left[{ }^{3} \mathrm{H}\right] \mathrm{cRNA}$ made from $\lambda \mathrm{CS} 17 \mathrm{C}-2$ and $\lambda \mathrm{CS} 17 \mathrm{C}-9$ to polytene chromosomes from $\operatorname{In}(1) D 6 j$. These clones contain inserts from opposite sides of the inversion breakpoint. Fig. 1c and d show hybridizations done with $\lambda$ CS17C-2 and $\lambda$ CS17C-9, respectively. $\lambda$ CS17C -2 hybridized only at the distal breakpoint, indicating that these sequences are within the inverted segment. $\lambda$ CS17C-9 hybridized only at the proximal breakpoint, indicating that the sequences cloned in this phage are outside the inversion. Taken together, these results indicate that $\lambda C S 17 \mathrm{C}-2$ is distal to $\lambda \mathrm{CS} 17 \mathrm{C}-9$ (Fig. 4a).

Six mutant alleles of the Beadex locus associated with insertions in a 500-base-pair region. As reported above, the spontaneous mutation $B x^{2}$ is associated with the insertion of two gypsy transposons at coordinates -0.5 and -1.5 . To analyze the restriction maps of three other spontaneous $B x$ alleles $\left(B x^{I}, B x^{3}, B x^{M}\right)$, one heat-induced allele $\left(B x^{J}\right)$, and one allele of unknown origin $\left(B x^{46}\right)$, we probed whole genome blots of DNA from each of these strains with overlapping phage clones from the Canton-S library. The four clones that we selected, $\lambda$ CS17C-13, $\lambda$ CS17C-24, $\lambda C S 17 C-19$, and $\lambda C S 17 C-9$, span the entire 49-kb cloned region (Fig. 4a). DNA from $B x^{2}$ flies, as well as Canton-S and Inscy $w$ flies, were included in this analysis. We included Inscy $w$ because the spontaneous allele $B x^{M}$ originated in this stock (we used the Inscy $w B x^{M}$ stock to isolate DNA for our analysis of the $B x^{M}$ mutation). Any differences between Inscy $w$ and Inscy $w B x^{M}$ are almost certainly associated with the occurrence of this mutation.

Figure 5 shows representative blots which were hybridized with ${ }^{32} \mathrm{P}$-labeled $\lambda$ CS17C-24 DNA. Note that this clone contains DNA from the region between coordinates -6.6 and +6.4 , within which the gypsy elements are inserted in $B x^{2}$. As expected from the composite restriction map in Fig. $4 \mathrm{a}$, two PvuI fragments $(10.4$ and $2.5 \mathrm{~kb})$ and three SmaI fragments $(8.0,7.2$, and $1.5 \mathrm{~kb})$ in Canton-S DNA showed homology to $\lambda \mathrm{CS} 17 \mathrm{C}-24$. Inscy $w$ flies, which are also $\mathrm{Bx}^{+}$, showed the same set of homologous fragments (the $2.0-\mathrm{kb}$ SmaI fragment in Inscy $w$ differs from the 1.95-kb fragment of Canton-S only by the 50- to 100-base-pair deletion discussed above).

When hybridized with $\lambda$ CS17C-24 DNA, each of the $B x$ 
mutant DNA digests exhibited restriction patterns different from those observed with Canton-S DNA. As expected, the 10.4-kb PvuI fragment $(-7.4$ to +3.0$)$ and the 7.2-kb SmaI fragment ( -7.2 to 0.0 ) were missing in the $B x^{2}$ strain. In both cases the missing fragment was replaced by a single larger fragment which represents the insertion of two gypsy transposons (see restriction maps of $B x^{2}$ in Fig. $4 \mathrm{~b}$ and $\mathrm{CBx}^{2} 17 \mathrm{C}-1$ in Fig. 2). The other $B x$ mutants exhibited a similar pattern. In each case the 10.4-kb $P v u I$ and 7.2-kb $S m a I$ fragments were replaced by fragments of novel size, indicating that a rearrangement had occurred between coordinates -7.2 and 0.0 . As in $B x^{2}$, these novel frgments can only be explained by the insertion of new DNA sequences in this segment. The restriction patterns we observed when mutant and wild-type DNAs were digested with EcoRI, SacI, HindIII (data not shown), and BamHI (see below) confirmed this conclusion and further defined the sites at which the new sequences had inserted.

Figure 6 shows a whole genome blot done with BamHIdigested genomic DNAs and probed with end-labeled, BamHI-cut p24R8.0B. This plasmid subclone contains the 8.0-kb EcoRI fragment $(-6.6$ to +1.4$)$ from $\lambda C S 17 C-24$ inserted at the EcoRI site of pUC8 (42). End-labeled, BamHI-cut plasmid was used to give uniform labeling of different-sized genomic BamHI fragments on the blot. Canton-S DNA contains five Bam HI fragments $(9.0,5.0,1.8$,

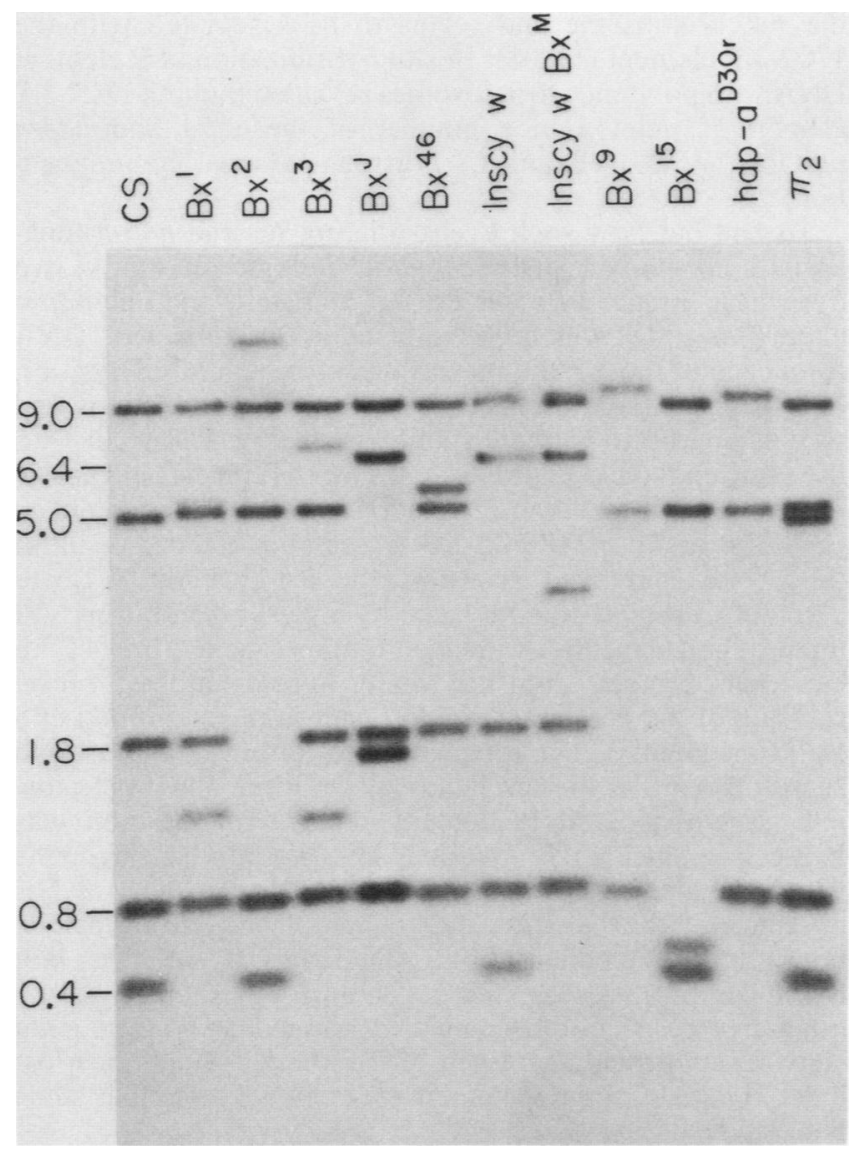

FIG. 6. BamHI-cut Beadex mutant and wild-type DNAs were probed with BamHI-digested p24R8.0B DNA which had been labeled at the BamHI ends with [ $\left.{ }^{32} \mathrm{P}\right] \mathrm{dGTP}$ by using the Klenow fragment of DNA polymerase I. This clone contains sequences which lie between coordinates -6.6 and +1.4 .
0.8 , and $0.4 \mathrm{~kb}$ in length) which are homologous to this probe. $B x^{J}$, Inscy $w$, and Inscy $w B x^{M}$ DNA have no BamHI site at coordinate +5.8 due to a simple polymorphism, resulting in the appearance of a $6.4-\mathrm{kb} B$ am $\mathrm{HI}$ fragment instead of the $5.0-\mathrm{kb}$ fragment of Canton-S. This restriction site polymorphism has no bearing on the $B x$ phenotype of these strains, since both $B x^{+}$and $B x$ mutant strains possess it. The 0.4-kb BamHI fragment $(-2.0$ to -1.6$)$ is missing in $B x^{I}, B x^{3}, B x^{J}, B x^{46}$, and Inscy $w B x^{M}$. Since the $0.4-\mathrm{kb}$ fragment is the only $B a m \mathrm{HI}$ fragment within the -7.2 to 0.0 segment which is altered in these $B x$ mutant strains, it must contain the sites at which the insertions occur in each of the alleles. The positions of each of the insertions are indicated on the composite restriction maps in Fig. 4b. Note that the distal gypsy element in $B x^{2}$ is located at coordinate -1.5 , very close to the $0.4-\mathrm{kb} B a m H I$ fragment $(-2.0$ to -1.6$)$. Thus, each of these six $B x$ mutations is associated with an insertion in the 500-base-pair interval between coordinates -2.0 and -1.5 .

In $49 \mathrm{~kb}$ of DNA surrounding this 500 -base-pair segment, we found few significant differences between the restriction maps of $B x$ mutant DNAs and Canton-S DNA (see Fig. 4b for composite maps.) In several instances $B x$ mutant strains were found to possess restriction sites not found in Canton-S and vice versa. However, with the exception noted below, both forms of each polymorphism were found among the three $\mathrm{Bx}^{+}$strains examined (Canton-S, Inscy $w$, and $\pi_{2}$ ). Therefore, none of these simple polymorphisms is related to the $B x$ phenotype of the flies that possess them.

A more complex loss of restriction sites was found in the $B x^{2}$ and $B x^{46}$ strains (see Fig. 4b). In these mutants, the loss of three EcoRI sites, a single HindIII site, and a PvuI site was due to the deletion of ca. $1.6 \mathrm{~kb}$ of DNA in the region between coordinates -17.8 and -15.8 . Even though $B x^{2}$ and $B x^{46}$ were isolated independently and possess different inserted elements (see below), these two deletions appear to be identical, as surmised by blot hybridization analysis (data not shown). The -17.8 to -15.8 interval is identical to Canton-S in each of the other $B x$ mutants examined. However, since we did not find this deletion in any of the $B x^{+}$ strains that we examined, we cannot exclude the possibility that it plays a role in manifesting wing scalloping in these two strains.

The nature of DNA sequences inserted at the Beadex locus. We were interested in determining whether any of the inserted DNA sequences described above were related to one another. To do this we compared their sizes and restriction maps. Restriction enzymes which do not cut within the DNA insertions give rise to only one novel-sized fragment when genomic DNA cut with them is examined by blot hybridization. The difference in size between this insertion-bearing fragment and the wild-type fragment is equal to the length of the inserted element. Based on the blot hybridization experiments described above, we estimated the size of the inserted elements. These results are summarized in Fig. 7. The insertions ranged in size from $5.2 \mathrm{~kb}$ in the $B x^{46}$ strain to over $12 \mathrm{~kb}$ in the $B x^{M}$ allele.

Enzymes which have recognition sites within the inserted elements give rise to two novel-sized fragments homologous to cloned Canton-S DNA. The lengths of these fragments can be used to deduce the positions of restriction sites within the inserted elements. For instance, the $B x^{46}$ insertion gave rise to two novel $P v u I$ fragments which are 9.6 and $6.0 \mathrm{~kb}$ in length. Each of these fragments had one end within the inserted element and the other in flanking DNA. Using probes on either side of this insertion $(\lambda C S 17 C-13$ on the 


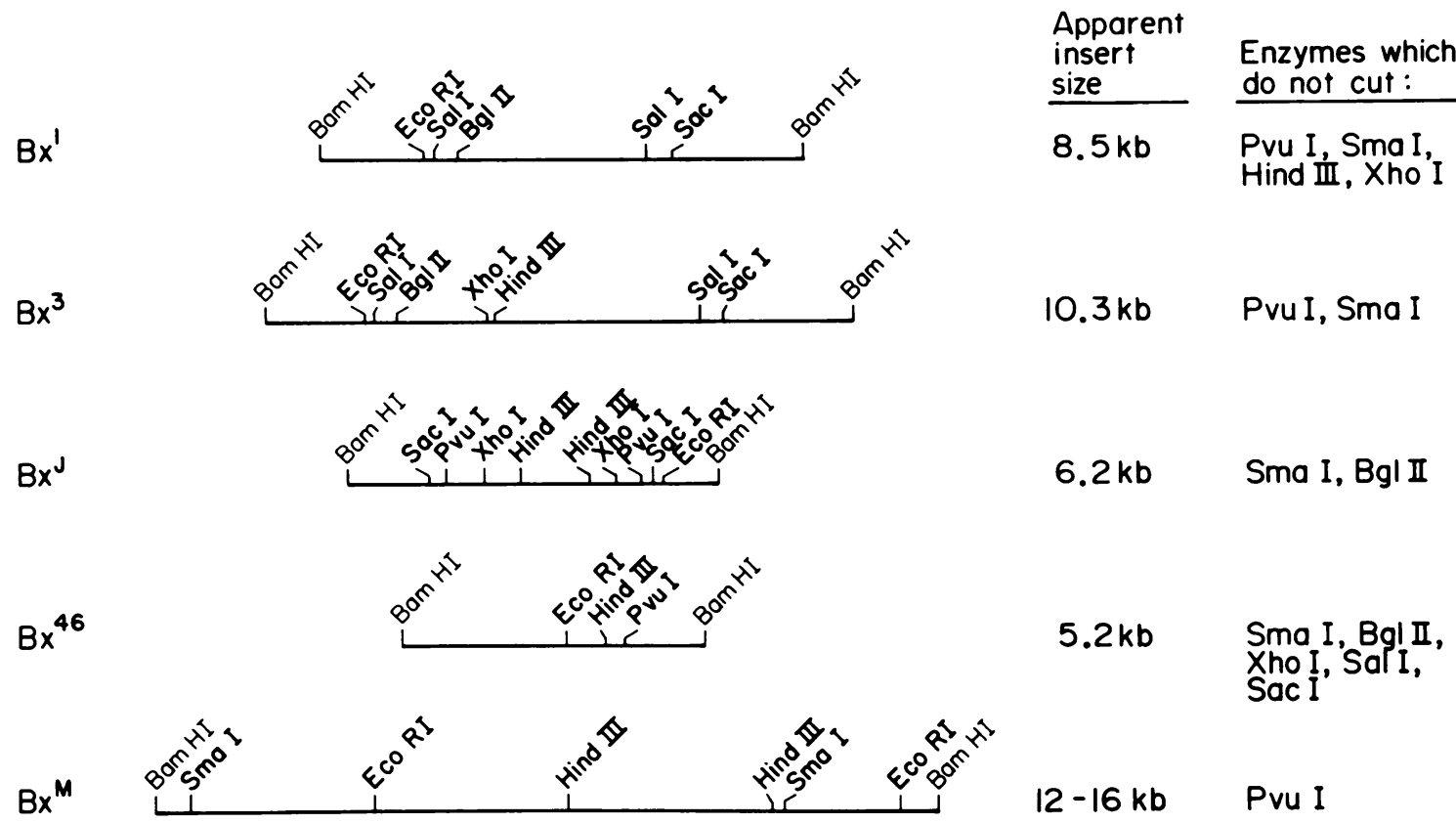

FIG. 7. Partial restriction maps of inserted elements associated with Beadex mutations. The BamHI sites at the termini of each map are those at coordinates -1.6 and -2.0 in the Canton-S map and are not part of the inserted elements. Each map is oriented with the right end toward the centromere. Enzymes which were tested but did not cut within the insertions are shown on the right.

distal side and pS25.1 on the proximal side), we determined which novel fragment arose from each end of the insertion (data not shown). This analysis positioned the 9.6-kb fragment distally and the $6.0-\mathrm{kb}$ fragment proximally and placed the single internal $P v u \mathrm{I}$ site about $1.4 \mathrm{~kb}$ distal to the BamHI site at coordinate -1.6 (see Fig. 7). Similar analyses with other restriction enzymes are summarized in Fig. 7. Since each inserted element possesses sequences that are not homologous to our Canton-S-derived cloned probes, we could not detect fragments which are internal to the inserted elements themselves. For this reason the restriction maps shown in Fig. 7 are incomplete. Nonetheless, it is apparent that the inserted elements are all different. None of their restriction maps bears any resemblance to that of the gypsy transposons inserted in $B x^{2}$ DNA. The $B x^{l}$ and $B x^{3}$ elements have five matching restriction sites and appear to differ only by an internal $1.8-\mathrm{kb}$ deletion-insertion. This deletion-insertion includes the region containing the unique $X h o I$ and HindIII sites found in the $B x^{3}$ element since the $B x^{1}$ element is not cut by these enzymes. The maps of both of these elements bear a resemblance to that of the retrovirus-like transposable element roo (28), also called B104 (36). The restriction map of the inserted element in $B x^{46}$ DNA is similar to published maps of the copia transposon and is approximately the same length (32). The insertion found in $B x^{J}$ has a restriction map like that of the $3 \mathrm{~S} 18$ retrovirus-like transposon (1). We are not aware of any transposable element with a restriction map similar to that of the element inserted in Inscy $w B x^{M}$ DNA.

Beadex and heldup- $a$ mutations induced by hybrid dysgenesis. The P element inserted at $17 \mathrm{C} 2-3$ in the $D$. melanogaster strain $\pi_{2}$ has recently been cloned and sequenced (31). Its position corresponds to coordinate -0.8 on our restriction map. Since this strain has normal wings, this $P$ element does not appear to disrupt either the $B x$ or the $h d p-a$ locus. However, the $\pi_{2} \mathrm{X}$-chromosome gives rise to both $B x$ and $h d p-a$ mutations at a frequency above $10^{-3}$ in the progeny of dysgenic hybrids $(4,11,13,38)$. This high rate is specific to the $\pi_{2}$ chromosome and seems to be associated with the 17C2-3 P element $(13,38)$. In situ hybridization of P element DNA with polytene chromosomes revealed that the 17C2-3 P element is deleted in a number of these $B x$ and $h d p-a$ mutants (W. Engels and C. Preston, personal communication; 12$)$.

To find out how such events disrupt $B x$ and $h d p$ - $a$ functional domains, we analyzed whole genome blots from two dysgenesis-induced $B x$ alleles $\left(B x^{9}\right.$ and $\left.B x^{15}\right)$ and one $h d p-a$ allele ( $h d p-a^{D 30 r}$ ) which was induced in the same way. DNA from each of these mutants was digested with BamHI, SacI, EcoRI, HindIII, SmaI, and PvuI in separate reactions and was compared to Canton-S and $\pi_{2}$ genomic DNA cut with the same enzymes. Figure 6 shows BamHI digests of each of these DNAs, which were hybridized with a ${ }^{32}$ P-end-labeled BamHI digest of p24R8.0B DNA (see above). As a result of the $2.9-\mathrm{kb} P$ element insertion, the $1.8-\mathrm{kb}$ band $(-1.6$ to +0.2 ) of Canton-S was replaced by a $4.7-\mathrm{kb}$ band in $\pi_{2}$. All three hybrid dysgenesis-induced mutants lacked this $4.7-\mathrm{kb}$ band, as expected from the in situ hybridizations. Precise excision of the $\mathrm{P}$ element would result in reconstitution of a $1.8-\mathrm{kb}$ fragment comigrating with the Canton-S fragment. No such fragment was found in any of the three mutant strains, indicating that each $P$ element excision or deletion was imprecise. Since each mutant is missing BamHI fragments which flank the $4.7-\mathrm{kb}$ fragment of $\pi_{2}$ (for instance $B x^{9}$ is missing both the 0.4 - and $9.0-\mathrm{kb}$ bands), the deletions include not only the P element but also flanking DNA. Similar blot hybridization analyses, using genomic DNA cut with the other five restriction enzymes mentioned above (data not shown), confirmed that each of the three mutants has lost most, if not all, of the P element (see below), as well as some flanking DNA.

Figure 8 shows the segments that were deleted. $B x^{15}$ is missing sequences on both sides of the $P$ element insertion site. This $2.0-\mathrm{kb}$ deletion certainly includes the sequences between coordinates -1.3 and +0.4 . The $B x^{9}$ deletion includes $1.2 \mathrm{~kb}$ of flanking DNA and overlaps the $B x^{15}$ 


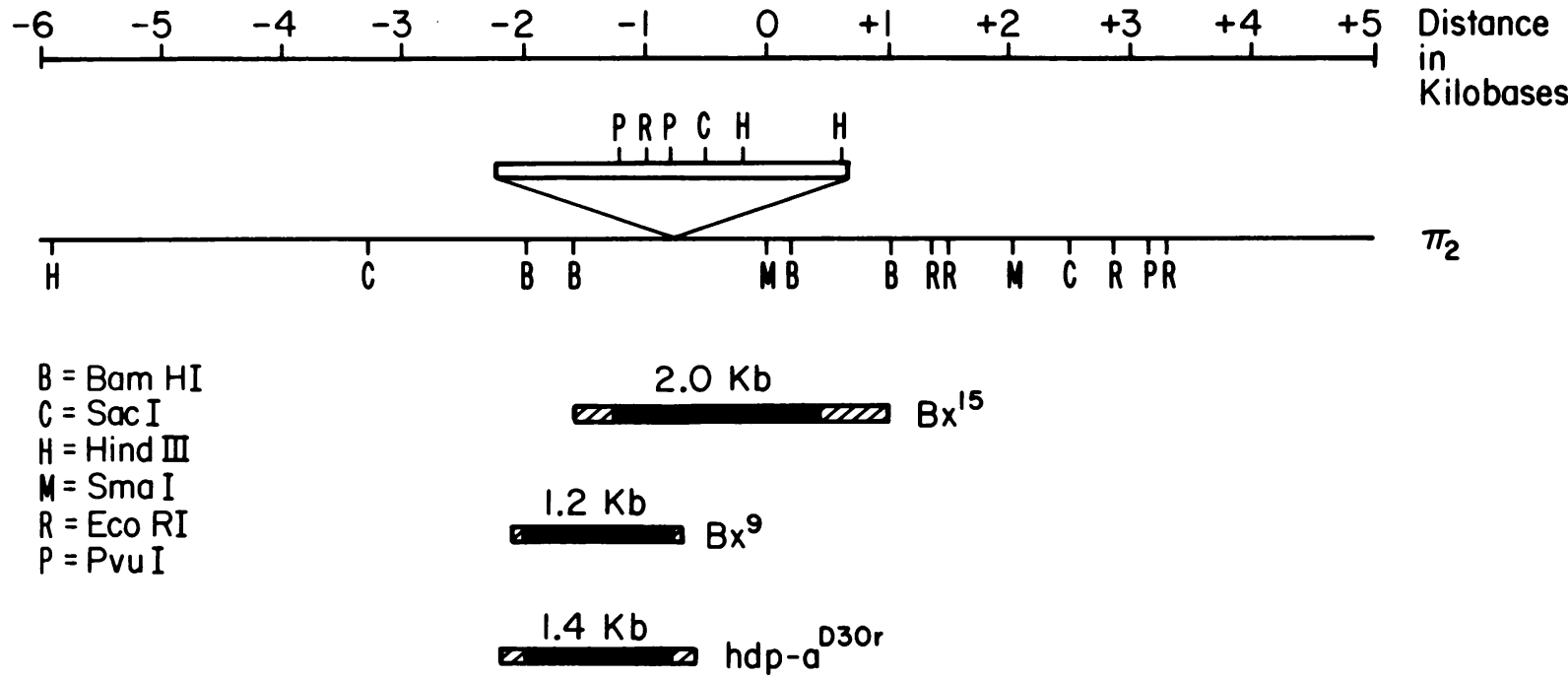

FIG. 8. Deletion maps of hybrid dysgenesis-induced mutants. The restriction map shown is that of DNA from $\pi_{2}$, the parental strain to each of the mutants shown. The coordinates are the same as those in Fig. 5. The P element is represented as an insertion at coordinate -0.8 . Dark bars indicate the regions known to be deleted in each of the mutants. The hatched segments indicate regions that may or may not be deleted. The size of each deletion, exclusive of the $2.9 \mathrm{~kb}$ of P element DNA that was lost, is indicated above the bar in each case. All sites outside of the deleted segment are identical to $\pi_{2}$ in each of the mutant strains. No restriction sites from the P element itself remain in any of the mutants.

deletion. In this mutant the proximal (right) boundary of the missing segment is within 100 base pairs of the $P$ element insertion site at -0.8 and may be coincident with it. The entire -1.5 to -2.0 segment, in which insertions occurred in six Beadex alleles described above, is deleted in $B x^{9}$.

The $h d p-a^{D 30 r}$ deletion has a right boundary indistinguishable from that of the $B x^{9}$ deletion, in this case with about 200 base pairs of uncertainty. Despite the fact that the $h d p-a^{D 30 r}$ mutant has no wing scalloping, this deletion appears to include the entire segment removed in $B x^{9}$. This is not surprising since genetic studies indicate that $h d p-a$ mutations are potent suppressors of $B x$ in cis (24). Thus, the phenotype of $h d p-a^{D 30 r}$ is consistent with that of a double mutation affecting both $h d p-a$ and $B x$. Note that the $h d p-a$ function is not disrupted in $B x^{9}$ and $B x^{15}$ since these alleles have no heldup wing phenotype and loss of the $h d p-a^{+}$function would suppress the wing-scalloping phenotype (both $B x^{9}$ and $B x^{15}$ mutants exhibit severe wing scalloping).

Blot hybridizations on $B x^{9}, B x^{15}$, and $h d p-a^{D 30 r}$ with probes covering the remainder of the $49-\mathrm{kb}$ cloned region failed to reveal any other differences between these strains and $\pi_{2}$.

\section{DISCUSSION}

The evidence presented above indicates that we isolated DNA sequences from both the Beadex and heldup-a loci of wild-type Drosophila melanogaster. We confirmed the identity of these sequences by blot hybridization analysis of one heldup- $a$ allele and eight Beadex alleles, all of which behave genetically as simple mutations at the gene locus. When compared with Canton-S DNA, each of the Beadex alleles exhibited alterations (insertions or deletions) within a 700base-pair segment which lies between coordinates -2.0 and -1.3 . No alterations relative to Canton-S were observed in this region in either of two $\boldsymbol{B x}^{+}$strains examined. Thus, disruption of this short segment is highly correlated with mutations in the Beadex locus. Examination of both the banding patterns on polytene chromosomes and quantitative blot hybridizations failed to detect any increase in the copy number of the $B x-h d p-a$ region in the mutant strains (unpublished data). Therefore, we think it is unlikely that any increases in gene dosage, which might contribute to the Beadex phenotype, accompanied these disruptions.

In several cases (Inscy $w B x^{M}, B x^{9}$, and $\left.B x^{15}\right)$, we were able to compare mutants with the parental strains from which they were isolated. Gross changes, coincident with the mutation event, should be detected as differences in the restriction maps of the mutant and parental strains. In each case we found that, over the entire 49-kb interval, the mutant strains differed from their parental strains only by the insertions and deletions mentioned above.

Although the parental strain for the mutant allele $B x^{2}$ is not available, it is known that this mutation behaves genetically as a gypsy transposon insertion in that it is suppressed by the $s u(H w)$ mutation $(23,25,29)$. Our molecular analysis detected gypsy transposon insertions in this strain at coordinates -0.5 and -1.5 . The -1.5 insertion is within the segment deleted in the $B x^{9}$ mutation and thus is near or within the Beadex functional domain. On the basis of these facts we suggest that the gypsy insertion at -1.5 is responsible for the $B x^{2}$ mutation. Since gypsy elements are known to disrupt gene function at a distance without physically disrupting the structural locus itself, it is possible that the +0.5 element also plays a role in the $B x^{2}$ mutation (2).

No parental strains are available for comparison with the mutant alleles $B x^{I}, B x^{3}, B x^{J}$, or $B x^{46}$. Each of these strains differs from Canton-S by DNA insertions within the -2.0 to -1.6 segment. The close proximity of these insertions to one another and to the Beadex locus itself (as defined by deletions) strongly suggests that they are within sequences required for the regulatory function of the Beadex locus. However, it is conceivable that these insertions do not physically disrupt the Beadex locus but rather are outside the regulatory domain and act at a distance to disrupt the normal Beadex function. Also, we cannot exclude the possibility that the true lesions in these strains are too small to detect by our blotting analysis and that these insertions, although close to the Beadex locus, do not affect it. 
Genetic analysis has indicated that Beadex mutations result in an increase in gene activity (24). Mutations in the nearby heldup- $a$ gene suppress the cis allele of the Beadex locus, suggesting that heldup- $a$ encodes the structural gene activated by $B x$ mutations. We showed that deletion of the segment of DNA between coordinates -2.1 and -0.7 (the $B x^{9}$ strain) is sufficient to elicit a strong dominant Beadex phenotype. This suggests that the normal function of these sequences is to repress heldup $-a^{+}$activity. Lifschytz and Green found that large chromosomal deficiencies which include both Beadex and heldup-a exhibit no dominant Beadex phenotype (24). The dominant wing scalloping found in $B x^{9}$ and the normal wing position of these flies strongly suggest that the $h d p-a^{+}$locus is not disrupted by this deletion. The $B x^{15}$ deletion, which removes $2.0 \mathrm{~kb}$ of DNA between +1.0 and -1.6 , has a phenotype very similar to $B x^{9}$, indicating that it also leaves $h d p-a^{+}$intact.

In contrast to $B x^{9}$ and $B x^{I 5}$ the $h d p-a^{D 30 r}$ mutant exhibits a fully penetrant wing position abnormality and no wing scalloping. Our blot hybridization analysis of this mutant indicates that it is deficient for the entire region lost in the $B x^{9}$ deletion. However, the $h d p-a^{D 30 r}$ deletion is about 200 base pairs larger than that of $B x^{9}$. We suggest that this deletion removes sequences from both the Beadex and heldup- $a$ domains and that the loss of heldup- $a^{+}$function precludes the expression of the Beadex phenotype. An alternative interpretation of this mutant would place the true $h d p$ - $a$ mutation outside the deleted segment. In this case the occurrence of the imprecise $P$ element excision-deletion would be merely coincidental. Since deletion events like the one in $h d p-a^{D 30 r}$ occur at a frequency of only $10^{-3}$, we think it unlikely that such an event coincided with an independent hdp-a mutation.

Given the above caveat, the segment of the $h d p-a^{+}$ functional domain removed in $h d p-a^{D 30 r}$ must be within DNA which is not deleted in $B x^{9}$ or $B x^{15}$ (since both of these mutants are $h d p-a^{+}$). This segment includes DNA between coordinates -2.0 and -2.3 . This suggests that sequences only a short molecular distance from the Beadex locus (less than 1,600 base pairs) are necessary for manifestation of the Beadex mutant phenotype. This position agrees well with the recombinational mapping (24) which placed an hdp-a mutation 0.0045 map units distal to Beadex.

The close molecular proximity of these two loci supports the model proposed by Lifschytz and Green (24), wherein the wild-type Beadex locus functions as a cis-acting negative regulatory element for the heldup-a gene. This model predicts that deletion of Beadex sequences would increase the amount of heldup $-a^{+}$activity which would in turn result in a wing-scalloping phenotype. Deletions including heldup- $a$, such as $h d p-a^{D 30 r}$, would obviate the possibility of hyperactivity and thus suppress Beadex mutations in cis.

Although it is clear from this analysis that some portion of the Beadex locus lies between coordinates -2.1 and -0.7 , this does not place any limits on the extent of the Beadex functional domain. The inversion $\operatorname{In}(1) D 6 j$, which was derived from the $\pi_{2}$ strain, is informative in this regard. The proximal breakpoint of this inversion is probably located within the $\mathrm{P}$ element inserted at coordinate -0.8 and undoubtedly lies between coordinates -1.6 and +0.2 (W. Engels and C. Preston, personal communication). This breakpoint disrupts the heldup- $b$ gene but not heldup- $a$ or Beadex (the heldup- $b$ gene is closely linked to heldup- $a$, and these mutants have a similar phenotype; however, heldup- $b$ mutations are complemented by heldup- $a$ and fail to suppress Beadex) (13; unpublished observations). This means that the Beadex and heldup- $a$ functional domains can extend no farther rightward than +0.2 . If we assume that Beadex sequences are found only to the right of heldup- $a$, the Beadex locus is entirely confined to the region between coordinates -2.3 and +0.2 . Of course, we have not proven that portions of the Beadex functional domain do not lie both to the right and left of heldup-a.

Our analysis of Beadex and heldup- $a$ alleles induced by hybrid dysgenesis revealed that these mutations result from imprecise excision or deletion of a nearby $\mathrm{P}$ element. Previous studies on the excision of $P$ elements detected precise excision events $(31,35,37)$ and imprecise events which left behind a portion of the $P$ element and did not remove any flanking sequences $(12,37)$. We showed that the events associated with the $B x^{9}, B x^{15}$, and $h d p-a^{D 30 r}$ mutations removed sequences which were adjacent to the $P$ element in the parental strain. In one case $\left(B x^{15}\right)$ sequences from both sides of the $\mathrm{P}$ element were clearly deleted. We believe that each of these mutants lost the entire $P$ element at -0.8 . No restriction sites from the $P$ element were detected in the mutant DNAs (including a HindIII site only 39 base pairs from the terminus), and in situ hybridizations of labeled $P$ element DNA to these mutant chromosomes failed to detect any homology at $17 \mathrm{C}$ (W. Engels and C. Preston, personal communication). Such imprecise excision events provide a novel means for isolating both Beadex and heldup-a mutations at a high frequency $(11,13,38)$. Molecular analysis of mRNA encoded by the $B x-h d p-a$ region of these mutants should be useful in determining the structural relationship between the Beadex and heldup-a loci. In particular, we hope to determine whether Beadex mutations affect sequences within or outside transcribed regions and whether the quantity or size of transcripts are affected. Resolution of these questions will lead to greater insight into the molecular role of the Beadex locus and help us to distinguish between transcriptional, post-transcriptional, and translational mechanisms for its effect on the level of $h d p-a^{+}$activity.

\section{ACKNOWLEDGMENTS}

We thank I. S. Margitich for expert technical assistance with electron microscopy. We are indebted to W. Bender, K. O'Hare, and G. Rubin for generously providing cloned DNA. W. R. Engels has been exceptionally helpful; we thank him for communicating results before publication and for giving us mutant fly stocks. We thank B. J. Bond, M. D. Garfinkel, E. Meyerowitz, S. Sharp, and B. Wold for their helpful comments on this manuscript. We thank all of our colleagues at Caltech for their comments and insights.

This work was supported by a National Research Service Award (GM-07616) and a Public Health Service grant (GM-10991) from the National Institutes of Health.

\section{LITERATURE CITED}

1. Bell, J. R., T. Schmidt, A. M. Bogardus, and M. Pelligrini. 1984. A new copia-like transposable element found in an rDNA gene unit. J. Cell. Biochem. 8:164.

2. Bender, W., M. Akam, F. Karch, P. A. Beachy, M. Peifer, P. Spierer, E. B. Lewis, and D. S. Hogness. 1983. Molecular genetics of the bithorax complex in Drosophila melanogaster. Science 221:23-29.

3. Benton, W. D., and R. W. Davis. 1977. Screening $\lambda$ gt recombinant clones by hybridization of single plaques in situ. Science 196:180-182.

4. Berg, R., W. R. Engels, and R. A. Kreber. 1980. Site-specific Xchromosome rearrangements from hybrid dysgenesis in Drosophila melanogaster. Science 210:427-429.

5. Bingham, P. M., R. Levis, and G. M. Rubin. 1981. Cloning of DNA sequences from the white locus of $D$. melanogaster by a novel and general method. Cell 25:693-704.

6. Blattner, F. R., B. G. Williams, A. E. Blechl, K. Denniston- 
Thompson, H. E. Faber, L. A. Furlong, D. J. Grunwald, D. O. Kieffer, D. D. Moore, E. L. Sheldon, and O. Smithies. 1977. Charon phages: safer derivatives of bacteriophage lambda for DNA cloning. Science 196:161-169.

7. Cline, T. W. 1978. Two closely linked mutations in Drosophila melanogaster that are lethal to opposite sexes and interact with daughterless. Genetics 90:683-698.

8. Davis. R. L., and N. Davidson. 1984. Isolation of the Drosophila melanogaster dunce chromosomal region and recombinational mapping of dunce sequences with restriction site polymorphisms as genetic markers. Mol. Cell. Biol. 4:358-367.

9. Davis, R. W., M. Simon, and N. Davidson. 1971. Electron microscope heteroduplex for mapping regions of base sequence homology. Methods Enzymol. 21:413-427.

10. Deak, I. I. 1977. Mutations of Drosophila melanogaster that affect muscles. J. Embryol. Exp. Morphol. 40:35-63.

11. Engels, W. R. 1979. Extrachromosomal control of mutability in Drosophila melanogaster. Proc. Natl. Acad. Sci. U.S.A. 76:4011-4015.

12. Engels, W. R. 1983. The P family of transposable elements in Drosophila. Annu. Rev. Genet. 17:315-344.

13. Engels, W. R., and C. R. Preston. 1981. Identifying P factors in Drosophila by means of chromosome breakage hotspots. Cell 26:421-426.

14. Gaissinovitch, A., and S. Gerschenson. 1928. Ein neues Allelmorph von Beadex bei Drosophila melanogaster. Biol. Zentralbl. 48:385-387.

15. Gall, J. G., and M. L. Pardue. 1971. Nucleic acid hybridization in cytological preparations. Methods Enzymol. 21:470-480.

16. Green, M. M. 1953. The Beadex locus in Drosophila melanogaster: genetic analysis of the mutant $B x^{r 49 K}$. Z. Indukt. Abstammungs Vererbungsl. 85:435-449.

17. Green, M. M. 1953. The Beadex locus in Drosophila melanogaster: on the nature of the mutants $B x^{\mathrm{r}}$ and $B x^{1}$. Genetics 38:91105.

18. Greenwald, I. S., P. W. Sternberg, and H. R. Horvitz. 1983. The lin-12 locus specifies cell fates in Caenorhabditis elegans. Cell 34:435-444.

19. Grosveld, F. G., H. M. Dahl. E. deBoer, and R. Flavell. 1981. Isolation of $\beta$-globin-related genes from a human cosmid library. Gene 13:227-237.

20. Hanahan, D., and M. Meselson. 1980. Plasmid screening at high colony density. Gene 10:63-67.

21. Ish-Horowicz, D., and J. F. Burke. 1981. Rapid and efficient cosmid cloning. Nucleic Acids Res. 9:2989-2998.

22. Jollos, V. 1933. Die Ubereinstimmung der bei Drosophila melanogaster nach Hitzeeinwirkung entstehenden Modifikation und Mutationen. Naturwissenschaften 21:831-834.

23. Lewis, E. B. 1981. Developmental genetics of the bithorax complex in Drosophila, p. 189-208. In D. D. Brown and C. R. Fox (ed.), Developmental biology using purified genes. Academic Press, Inc., New York.

24. Lifschytz, E., and M. M. Green. 1979. Genetic identification of dominant overproducing mutations: the Beadex gene. Mol. Gen. Genet. 171:153-159.

25. Lindsley, D. L., and E. H. Grell. 1968. Genetic variations of Drosophila melanogaster. Publ. no. 627. Carnegie Institute, Washington, D.C.

26. Maniatis, T., R. C. Hardison, E. Lacy, J. Lauer, C. O'Connell, D. Quon, G. K. Sim, and A. Efstratiadis. 1978. The isolation of structural genes from libraries of eukaryotic DNA. Cell 15:687701
27. Maxam, A. M., and W. Gilbert. 1980. Sequencing end-labeled DNA with base-specific chemical cleavages. Methods Enzymol. 65:449-560.

28. Meyerowitz, E. M., and D. S. Hogness. 1982. Molecular organization of a Drosophila puff site that responds to ecdysone. Cell 28:165-176.

29. Modolell, J., W. Bender, and M. Meselson. 1983. Drosophila melanogaster mutations suppressible by the suppressor of Hairy-wing are insertions of a 7.3 kilobase mobile element. Proc. Natl. Acad. Sci. U.S.A. 80:1678-1682.

30. Mullins, J. I., J. W. Casey, M. O. Nicholson, K. B. Burck, and N. Davidson. 1981. Sequence arrangement and biological activity of cloned feline leukemia virus proviruses from a virus-productive human cell line. J. Virol. 38:688-703.

31. O'Hare, K., and G. M. Rubin. 1983. Structures of P transposable elements and their sites of insertion and excision in the Drosophila melanogaster genomes. Cell 34:25-35.

32. Potter, S. S., W. J. Brorein, Jr., P. Dunsmuir, and G. M. Rubin. 1979. Transposition of elements of the 412, copia and 297 dispersed repeated gene families in Drosophila. Cell 17:415427.

33. Rigby, P. W. J., M. Dieckmann, C. Rhodes, and P. Berg. 1977. Labeling deoxyribonucleic acid to high specific activity in vitro by nick translation with DNA polymerase I. J. Mol. Biol. 113:237-251.

34. Rozek, C. R., and N. Davidson. 1983. Drosophila has one myosin heavy-chain gene with three developmentally regulated transcripts. Cell 32:23-34.

35. Rubin, G. M., M. G. Kidwell, and P. M. Bingham. 1982. The molecular basis of P-M hybrid dysgenesis: the nature of induced mutations. Cell 29:987-994.

36. Scherer, G., C. Tschudi, J. Perera, H. Delius, and V. Pirrota. 1982. B104, a new dispersed repeated gene family in Drosophila melanogaster and its analogies with retroviruses. J. Mol. Biol. 157:435-451.

37. Searles, L. L., R. S. Jokerst, P. M. Bingham, R. A. Voelker, and A. L. Greenleaf. 1982. Molecular cloning of sequences from a Drosophila RNA polymerase II locus by P element transposon tagging. Cell 31:585-592.

38. Simmons, M. J., J. D. Raymond, N. A. Johnson, and T. M. Fahey. 1984. A comparison of mutation rates for specific loci and chromosome regions in dysgenic hybrid males of Drosophila melanogaster. Genetics 106:85-94.

39. Smith, R. F., and R. J. Konopka. 1982. Effects of dosage alterations at the per locus on the period of the circadian clock of Drosophila. Mol. Gen. Genet. 185:30-36.

40. Southern, E. M. 1975. Detection of specific sequences among DNA fragments separated by gel electrophoresis. J. Mol. Biol. 98:503-518.

41. Steinmetz, M., A. Winoto, K. Minard, and L. Hood. 1982. Clusters of genes encoding mouse transplantation antigens. Cell 28:489-498.

42. Vierira, J., and J. Messing. 1982. The PUC plasmids, an M13mp7-derived system for insertion mutagenesis and sequencing with synthetic universal primers. Gene 19:259-268.

43. Wensink, P. C., D. J. Finnegan, J. E. Donelson, and D. S. Hogness. 1974. A system for mapping DNA sequences in the chromosomes of Drosophila melanogaster. Cell 3:315-325.

44. Yamamoto, K. R., B. M. Alberts, R. Benzinger, L. Lawhorne, and G. Treiber. 1970. Rapid bacteriophage sedimentation in the presence of polyethylene glycol and its application to large-scale virus purification. Virology 40:734-744. 